
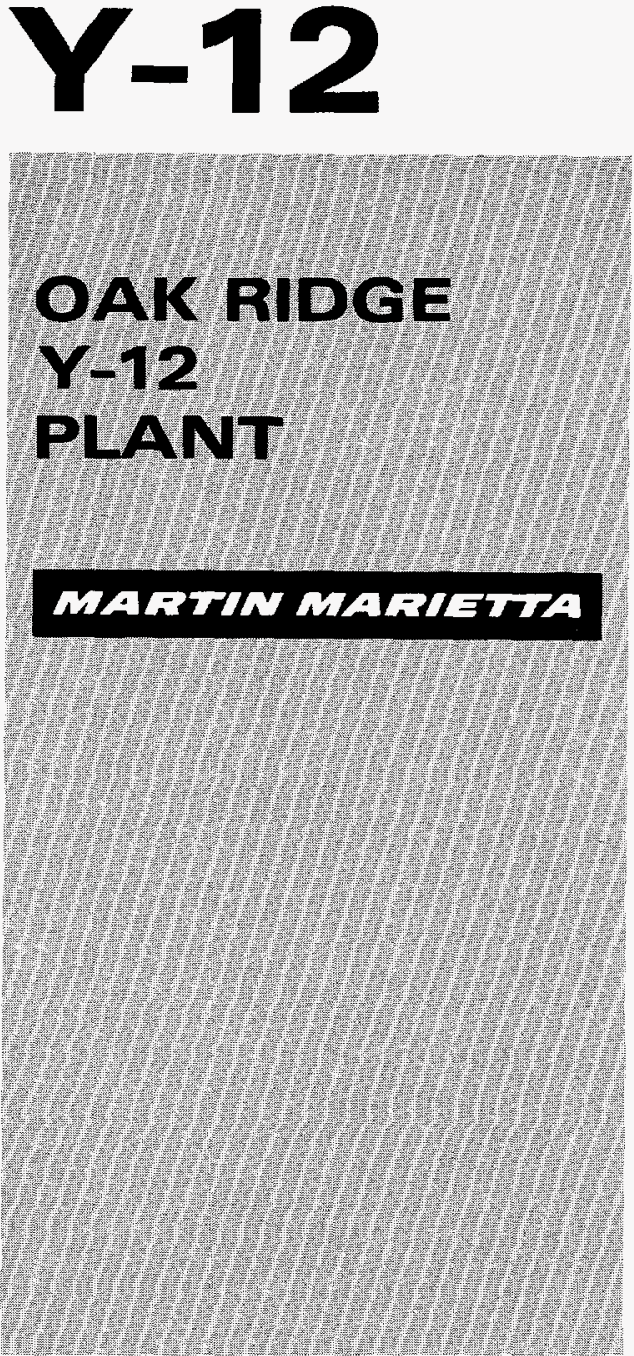

\title{
THERMAL DECOMPOSITION OF MERCURIC SULFIDE
}

\author{
J. H. Leckey \\ and
}

L. E. Nulf

\section{Chemistry and Chemical Engineering Department Development Organization}

\section{DISCLAIMER}

This report was prepared as an account of work sponsored by an agency of the United States Government. Neither the United States Government nor any agency thereof, nor any of their employees, makes any warranty, express or implied, or assumes any legal liability or responsibility for the accuracy, completeness, or usefulness of any information, apparatus, product, or process disclosed, or represents that its use would not infringe privately owned rights. Reference herein to any specific commercial product, process, or service by trade name, trademark, manufacturer, or otherwise does not necessarily constitute or imply its endorsement, recommendation, or favoring by the United States Government or any agency thereof. The views and opinions of authors expressed herein do not necessarily state or reflect those of the United States Government or any agency thereof.

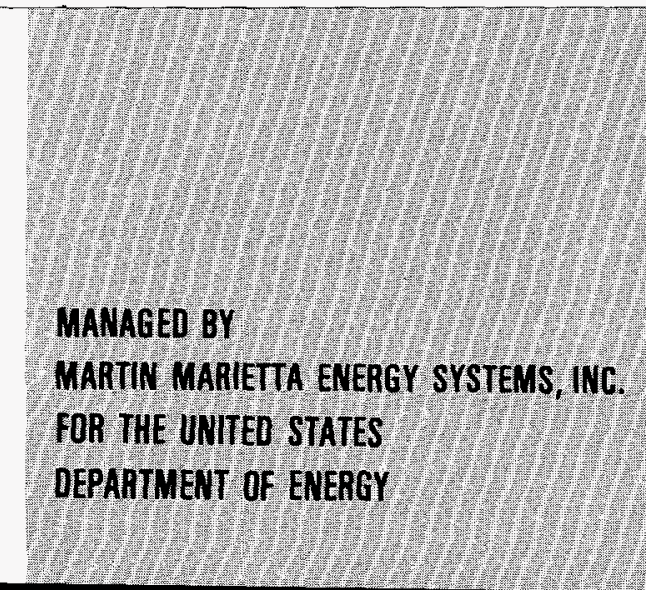

Prepared by the

P.O. Box 2009, Oak Ridge, Tennessee 37831 managed by

Martin Marietta Energy Systems, Inc. for the

U. S. DEPARTMENT OF ENERGY under contract DE-AC05-84OR21400

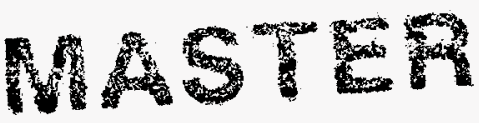




\section{DISCLAIMER}

This report was prepared as an account of work sponsored by an agency of the United States Government. Neither the United States Government nor any agency thereof, nor any of their employees, makes any warranty, express or implied, or assumes any legal liability or responsibility for the accuracy, completeness, or usefulness of any information, apparatus, product, or process disclosed, or represents that its use would not infringe privately owned rights. Reference herein to any specific commercial product, process, or service by trade name, trademark, manufacturer, or otherwise, does not necessarily constitute or imply its endorsement, recommendation, or favoring by the United States Government or any agency thereof. The views and opinions of authors expressed herein do not necessarily state or reflect those of the United States Government or any agency thereof. 


\section{DISCLAIMER}

Portions of this document may be illegible in electronic image products. Images are produced from the best available original document. 


\section{J. H. Leckey}

and

L. E. Nulf

Chemistry and Chemical Engineering Department

Development Organization

Prepared by the

Oak Ridge Y-12 Plant

P.O. Box 2009, Oak Ridge, Tennessee 37831-8169

managed by

MARTIN MARIETTA ENERGY SYSTEMS, INC.

for the

U.S. DEPARTMENT OF ENERGY

under contract DE-AC05-84OR21400 

CONTENTS

LIST OF FIGURES $\ldots \ldots \ldots \ldots \ldots \ldots \ldots \ldots \ldots \ldots \ldots \ldots \ldots \ldots \ldots \ldots \ldots \ldots$ vi

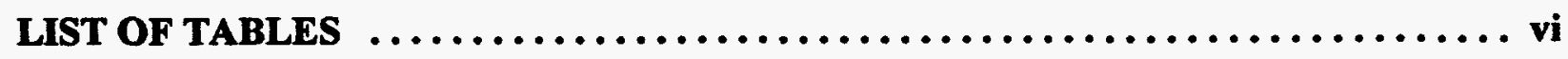

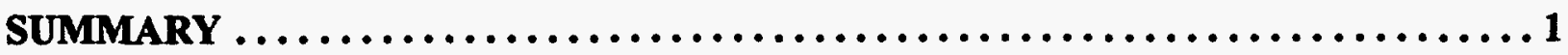

INTRODUCTION $\ldots \ldots \ldots, \ldots, \ldots, \ldots, \ldots, \ldots, \ldots, \ldots, \ldots, \ldots, \ldots, \ldots, \ldots, 2$

THERMODYNAMIC STABILTYY OF HgS $\ldots \ldots \ldots \ldots \ldots \ldots \ldots \ldots \ldots \ldots \ldots$

EXPERIMENTAL DESIGN $\ldots \ldots \ldots \ldots \ldots \ldots \ldots \ldots \ldots \ldots \ldots \ldots \ldots \ldots \ldots, \ldots, \ldots$

THERMAL DECOMPOSITION EXPERIMENTS $\ldots \ldots \ldots \ldots \ldots \ldots \ldots \ldots \ldots \ldots ., 8$

PRACTICAL RESULTS $\quad \ldots \ldots \ldots \ldots \ldots \ldots \ldots \ldots \ldots \ldots \ldots \ldots \ldots \ldots \ldots \ldots \ldots \ldots$

COMPARISON WITH LARGE-SCALE STUDIES $\ldots \ldots \ldots \ldots \ldots \ldots \ldots \ldots \ldots$

CONCLUSIONS AND FUTURE WORK $\ldots \ldots \ldots \ldots \ldots \ldots \ldots \ldots \ldots \ldots \ldots \ldots$

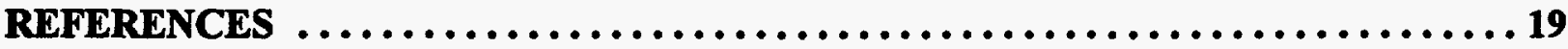




\section{LIST OF FIGURES}

Figure $\quad$ Page

1 Maximum thermal decomposition rate of $\mathrm{HgS}$ as a function of temperature at 4 selected flow rates

2 Schematic of apparatus used for thermal decomposition experiments

3 Thermal decomposition rate of $\mathrm{HgS}$ in nitrogen for a ramped temperature of $100^{\circ} \mathrm{C} / \mathrm{h}$ and a flow rate of $6.2 \mathrm{~L} / \mathrm{min}$

4 Rate-versus-time profiles at selected temperatures for several constant temperature runs

5 Rate, $\operatorname{Ln}\left(\right.$ Rate). and temperature as a function of time for a particular run at $335^{\circ} \mathrm{C}$

6 Arrhenius plot of rate constants determined from the time dependence of individual decomposition runs at constant temperature

7 Prediction of mercuric sulfide decomposition quantity as a function of time for several temperatures

\section{LIST OF TABLES}

Table

1 Summary of results of large-scale studies 


\section{SUMMARY}

The rate of thermal decomposition of mercuric sulfide $(\mathrm{HgS})$ has been measured at temperatures from $265^{\circ}$ to $345^{\circ} \mathrm{C}$. These data have been analyzed using a first-order chemical reaction model for the time dependence of the reaction and the Arrhenius equation for the temperature dependence of the rate constant. Using this information, the activation energy for the reaction was found to be $55 \mathrm{kcal} / \mathrm{mol}$. Significant reaction vessel surface effects obscured the functional form of the time dependence of the initial portion of the reaction.

The data and the resulting time-temperature reaction-rate model were used to predict the decomposition rate of $\mathrm{HgS}$ as a function of time and temperature in thermal treatment systems. Data from large-scale thermal treatment studies already completed were interpreted in terms of the results of this study. While the data from the large-scale thermal treatment studies were consistent with the data from this report, mass transport effects may have contributed to the residual amount of mercury which remained in the soil after most of the large-scale runs. 


\section{INTRODUCTION}

The thermal decomposition kinetics of mercury species is of interest to both personnel at the Oak Ridge Reservation and environmental researchers nationwide. At the Oak Ridge Y-12 Plant and surrounding areas, mercury is a contaminant in soils and debris. For wastes containing $>260$ ppm of total mercury and no orgaincs, the prescribed treatment (according to Environmental Protection Agency (EPA) regulations as delineated in 40 CFR part 268.42, Table $2^{1}$ ) is thermal desorption. If organics are also present in the waste, incineration or thermal desorption are both listed as acceptable treatment paths by the EPA, with incineration the preferred method. Most of the recent effort at Energy Systems has been in support of thermal desorption. This process usually involves heating the waste in a flowing gas system to an unspecified temperature for an unspecified time period. The mercury evolved during this process is then collected and disposed of by appropriate means. To optimize such a system, it is desirable to determine (among other things), in as much detail as possible, the decomposition kinetics of the mercury species likely to be present in the waste. Since mercuric sulfide (HgS) is suspected to be a major form for the mercury waste at and around the Oak Ridge Reservation, ${ }^{2}$ its thermal decomposition behavior is of particular importance.

Information on the thermal stability of $\mathrm{HgS}$ is also of general interest. This form of mercury has been prescribed by the EPA as an acceptable form for disposal in Subtitle D disposal facilities. ${ }^{3}$ As such, it is important to predict as accurately as possible its thermal stability both during processing for disposal and after it has been placed in a disposal area.

This report presents the thermodynamics of the stability of $\mathrm{HgS}$, describes a series of experiments performed to measure the rate of thermal decomposition of $\mathrm{HgS}$ at various temperatures, and interprets this information in terms of large-scale facilities that might be used for thermal desorption of waste that contains mercuric sulfide. Comparisons are made with existing data from several already completed large-scale studies. 


\section{THERMODYNAMIC STABILITY OF HgS}

Mercuric sulfide (HgS) decomposes into mercury and sulfur before melting by a process sometimes referred to as reactive sublimation. The decomposition of $\mathrm{HgS}$ proceeds according to the chemical equation

$$
\mathrm{HgS}(\mathrm{s})->\mathrm{Hg}(\mathrm{g})+1 / 2 \mathrm{~S}_{2}(\mathrm{~g})
$$

If one uses thermodynamic data listed in Ref. 4 and assumes that the change in heat capacity between products and reactants is independent of temperature, one can give the Gibbs free energy for this reaction as a function of temperature by the expression,

$$
\Delta G(R x n)=44.7-0.0521 T-0.00272 \ln (T / 298) \text {, }
$$

where $\Delta G(R \times n)$ is in $\mathrm{kcal} / \mathrm{mol}$ of $\mathrm{HgS}$, and $T$ is the temperature in Kelvin. At room temperature, $298 \mathrm{~K}, \Delta G(R x n)$ is $29 \mathrm{kcal} / \mathrm{mol}$. Such a positive value for $\Delta G(R x n)$ for a reaction that proceeds at constant temperature and pressure (which will be the case for most of the experimental runs in this study) is normally an indication that the reaction will not proceed to any significant extent, and the $\mathrm{HgS}$ is considered stable at room temperature.

It is common practice to determine the temperature at which $\Delta G(R x n)$ is zero. From Equation 2, it is easily shown that this event occurs at $585^{\circ} \mathrm{C}$. It is often tempting to suggest that this is the temperature at which the reaction might be expected to begin to proceed at a significant rate. However, this point indicates only the temperature at which (for an equilibrium mixture of $\mathrm{HgS}(\mathrm{s}), \mathrm{Hg}(\mathrm{g})$, and $\left.\mathrm{S}_{2}(\mathrm{~g})\right)$ the partial pressures of $\mathrm{Hg}(\mathrm{g})$ and $\mathrm{S}_{2}(\mathrm{~g})$ in atmospheres are given by the expression (ignoring fugacity effects),

$$
P_{\mathrm{Hg}} P_{\mathrm{S} 2}^{1 / 2}=1 .
$$

In actuality, the reaction rate may be significant at lower temperatures if the gaseous products are removed from the reaction area. Nonetheless, this type of analysis provides an indication of the general temperature regime likely to be useful in studying the decomposition reaction.

Another useful calculation to be performed before acquiring experimental kinetic data is the determination of the maximum reaction rate at a given temperature. Equation 3 is related to the equilibrium constant for Equation 1 by the expression,

$$
\Delta G(R x n)=-R T \ln (K),
$$

where $R$ is the gas constant and $K$ is the equilibrium constant given by the expression,

$$
K=P_{\mathrm{Hg}} P_{\mathrm{S} 2}^{1 / 2} \text {, }
$$

where non-ideal effects have again been ignored. Substituting Eq. 4 and 5 into Eq. 2, noting that 
the partial pressure of sulfur will be half that of mercury, and solving for $P_{\mathrm{Hg}}$ in atmospheres gives,

$$
P_{\mathrm{Hg}}=1.26 \exp (17.78-15,098 / \mathrm{T}) \text {. }
$$

Figure 1 shows a plot of $P_{\mathrm{Hg}}$ (labelled $\mathrm{P}(\mathrm{Hg})$ in the figure) versus temperature as calculated from Eq. 6.

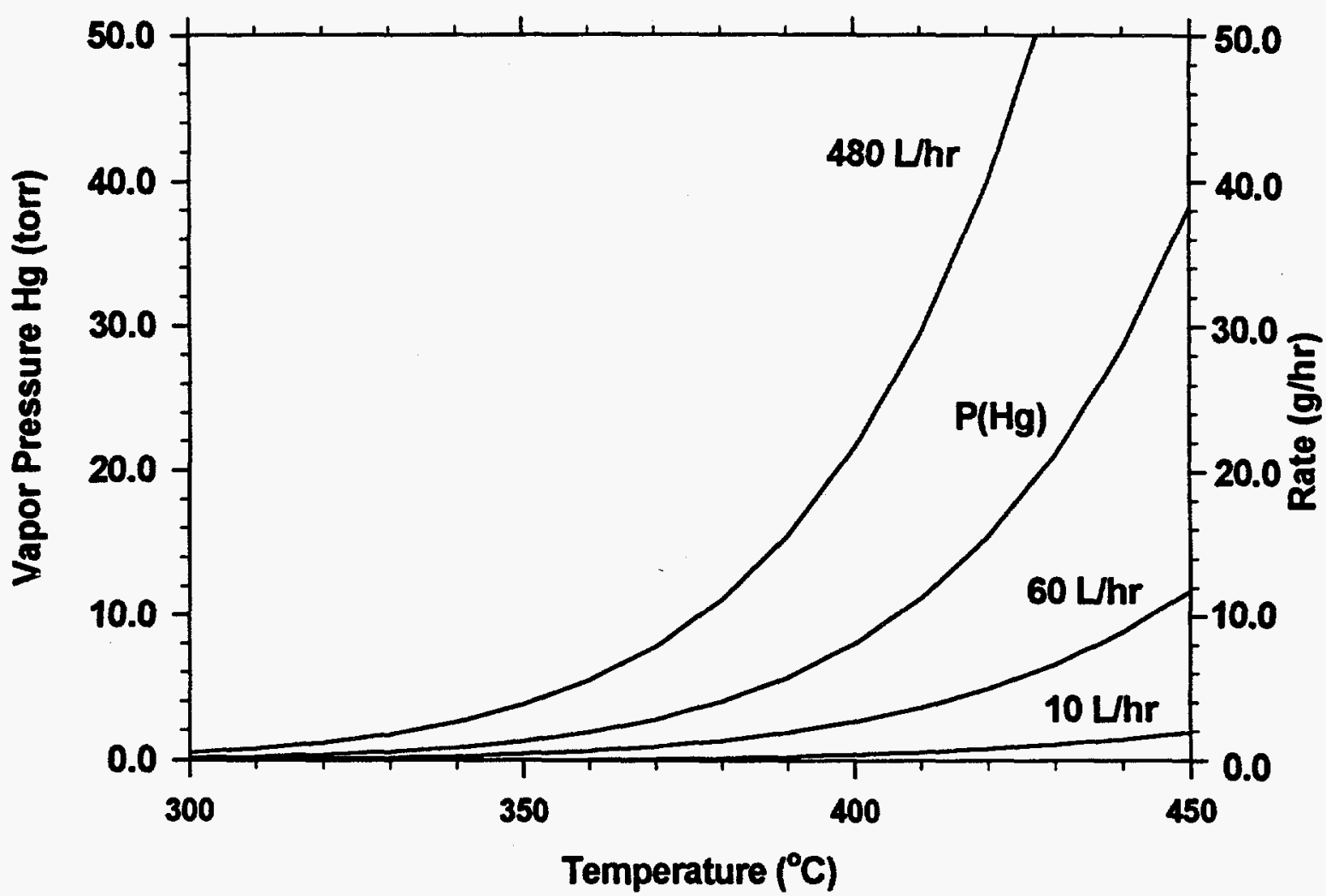

Fig. 1. Maximum thermal decomposition rate of $\mathrm{HgS}$ as a function of temperature at selected flow rates and partial pressure of $\mathrm{Hg}$ in equilibrium with $\mathrm{HgS}$ as a function of temperature. For the type of experiment used in this study, the equilibrium partial pressure of mercury and the carrier gas flow rate completely determine the maximum rate of the reaction.

Multiplying the partial pressure of mercury by the total gas-flow rate gives the maximum decomposition rate. In addition to the partial pressure curve, Figure 1 also shows the maximum decomposition rate for several flow rates. If the decomposition rate is observed to be near this maximum value, one can conclude that the mercuric sulfide dissociation rate is slow (or at least on the same order of magnitude) compared with the rate of transport of evolved gases by the carrier 
gas. Obviously, as the flow rate increases without bound, the chemical reaction rate will become slow compared to the mass transport rate (ignoring surface effects). Since this study seeks to study the mercuric sulfide dissociation kinetics, it will be desirable to design the experiments so that the observed decomposition rate is well below the maximum rates shown in Fig. 1. 


\section{EXPERIMENTAL DESIGN}

The HgS thermal decomposition experiments were designed to minimize gas transport effects and surface interaction effects. In an attempt to do this, the following principals were applied:

- small samples to minimize sample heating caused by heat produced by the reaction,

- light sample holder to allow reaction temperature to be attained rapidly,

- high surface area to volume for samples to minimize bulk diffusion effects,

- high flow rate and detector close to the sample to allow mercury to be detected soon after it evolves from the sample, and

- no unnecessary surfaces and no metal surfaces in the system to minimize mercury condensation.

Figure 2 is a schematic of the system that was designed, built, and assembled to study the reaction. Using this apparatus, the $\mathrm{HgS}$ decomposition can be followed by measuring the rate of formation of mercury. The furnace is a cylindrical clam-shell heater controlled by an Omega temperature programmer. A quartz tube $\sim 15 \mathrm{~cm}$ long by $3 \mathrm{~cm}$ diam passes through the center of the furnace. About $0.5-\mathrm{mg}$ samples of $\mathrm{HgS}$ are placed in a small, porcelain boat, which is introduced into the quartz tube inside the furnace. As the sample is decomposed, the decomposition products are swept down the quartz tube and out of the furnace. The flow is then split, the bulk of the sample exiting the system through an MKS manufactured flow meter followed by a sodium hypochlorite scrubber to the vent. The hypochlorite scrubber converts the gas-phase mercury to mercury (II) ions via an oxidation-reduction reaction, which also forms chloride ions from the hypochlorite. The result is a dilute solution of mercuric chloride. The rest of the sample is swept through an EPM Model 790 ultraviolet mercury detector, which monitors the mercury absorption rate at $253.7 \mathrm{~nm}$ as a function of time. The instrument has a dynamic mercury detection range of between 2 and $2000 \mu \mathrm{g} / \mathrm{m}^{3}$. Since a number of aromatic organic compounds absorb at this frequency, care must be taken to avoid introducing such materials into the system.

Preliminary to the $\mathrm{HgS}$ decomposition runs, elemental sulfur was heated in the system to test for the ultraviolet response of sulfur species, none of which was detected at the measurement frequency for the EPM. After passing through the detector, this portion of the flow also exited from the system, through another MKS flow meter, and then through a sodium hypochlorite scrubber.

Both the sample temperature, as read by a Type $\mathrm{K}$ thermocouple placed near the sample holder, and the mercury monitor output signal are transmitted through an AND converter to a personal computer (PC) for data acquisition and data processing. The reaction rate is the total gas-flow rate through the system (sum of the readings of the MKS flow monitors) multiplied by the concentration of mercury as read by the EPM. The total quantity of mercury evolved is the 
integral of this reaction rate over time. The reaction time, reaction temperature, mercury evolution rate, and quantity of mercury evolved are displayed in real time on the PC monitor. These data are also saved in a computer file for further data analysis.

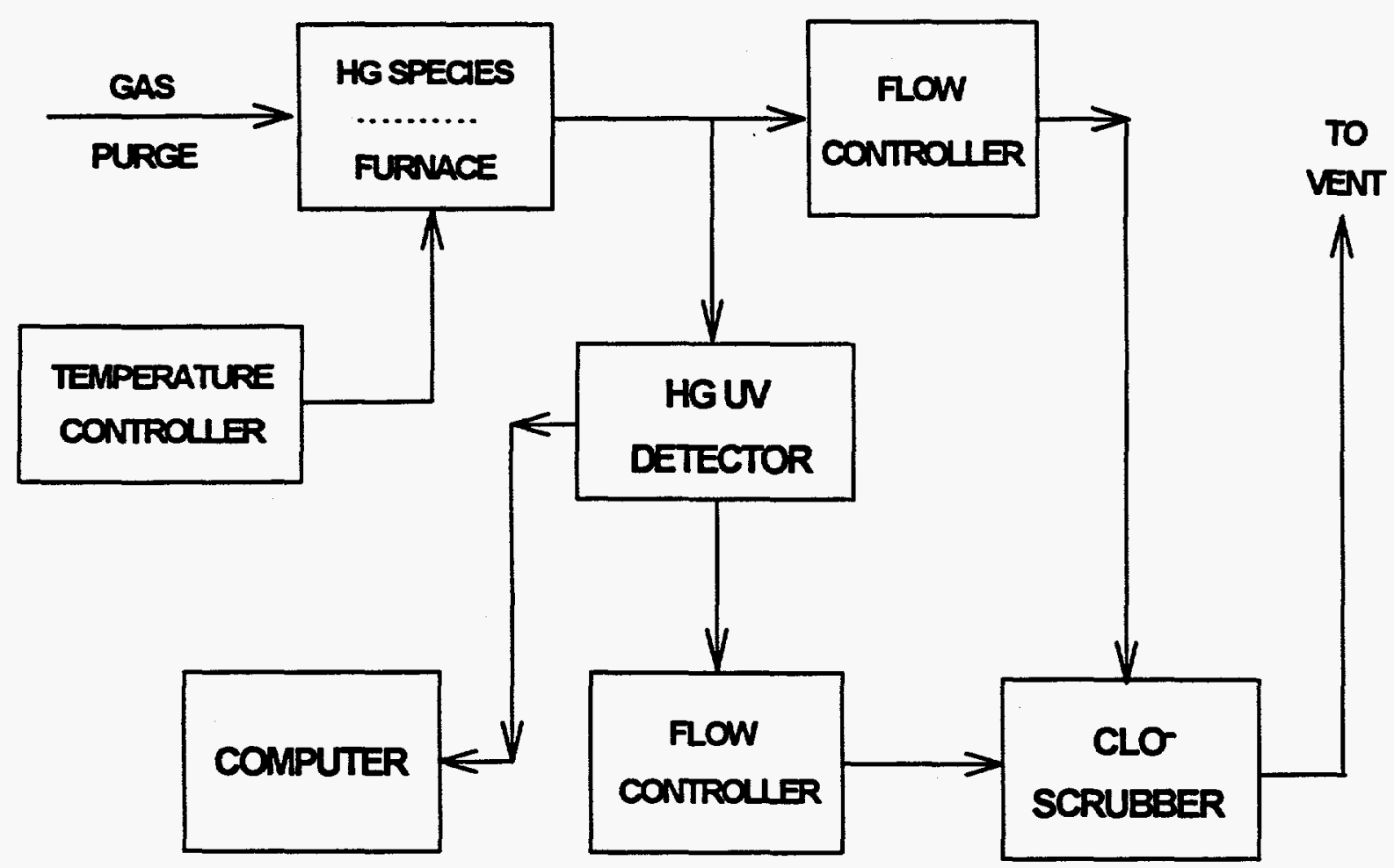

Fig. 2. Schematic of apparatus used for thermal decomposition experiments.

Most of the decomposition runs were performed at constant temperature; however, some of the scoping runs were performed with the temperature increasing with time at a constant rate. Constant temperature runs were performed by first allowing the furnace to heat to the prescribed temperature and then inserting the sample into the hot furnace, after which the sample typically required about $30 \mathrm{sec}$ to reach the reaction temperature. Carrier gases used were either air or nitrogen. A typical flow rate was $6 \mathrm{~L} / \mathrm{min}$ with $1 \mathrm{~L} / \mathrm{min}$ of the flow passing through the detector. 


\section{THERMAL DECOMPOSITION EXPERIMENTS}

An initial experiment was performed to determine the approximate range of temperatures over which the HgS thermal decomposition could be studied with the apparatus described in the last section. For this experiment, the sample temperature was ramped from room temperature at a rate of $100^{\circ} \mathrm{C} / \mathrm{h}$. Figure 3 shows the decomposition results for this experiment in terms of rate of mercury detected as a function of temperature.

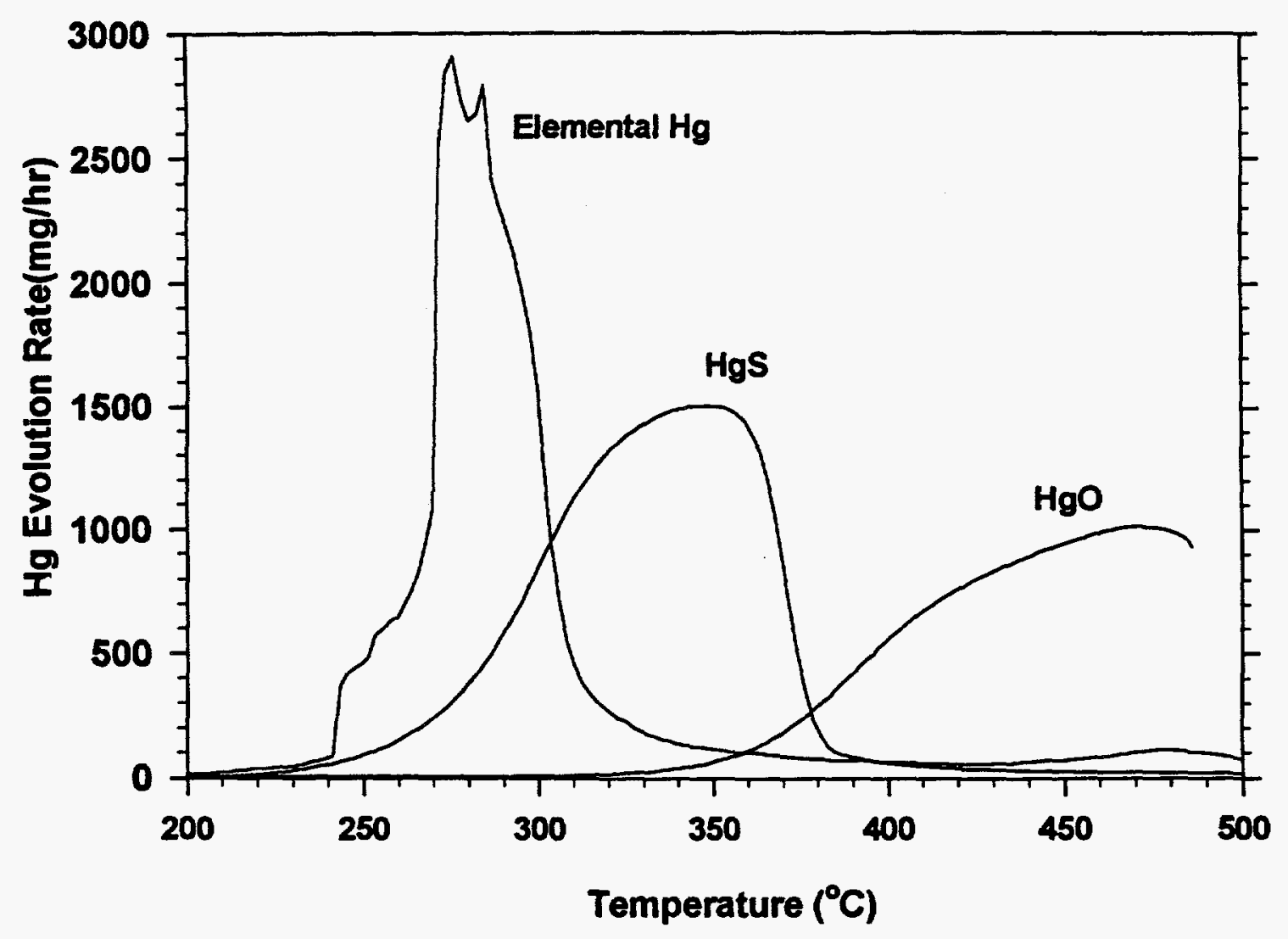

Fig. 3. Thermal decomposition rate of $\mathrm{HgS}$ in nitrogen for a ramped temperature of $100^{\circ} \mathrm{C} / \mathrm{h}$ and a flow rate of $6.2 \mathrm{~L} / \mathrm{min}$. The graph also shows, for reference, the decomposition rates of equal-size samples of elemental mercury and mercuric oxide ( $\mathrm{HgO})$. As the graph indicates, the rate of thermal decomposition of $\mathrm{HgS}$ is intermediate between that of elemental mercury and $\mathrm{HgO}$.

Obtaining quantitative rate data from this type of experiment is difficult; however, Fig. 3 shows that the $\mathrm{HgS}$ decomposition rate begins to become significant (i.e., measurable with the system used in the study) at $-220^{\circ} \mathrm{C}$. Note, referring to the partial pressure curve in Fig. 1 , that at $220^{\circ} \mathrm{C}$ the partial pressure is well below 1 torr, and even at $350^{\circ} \mathrm{C}$ it is only about 2 torr. This 
fact has two implications: 1 . The reaction rate is well below the thermodynamic maximum limit (which is desirable for these experiments), 2. by continually sweeping out the mercury vapor as it is formed at the reaction site, the decomposition reaction proceeds at a significant rate, even though the free energy for the standard state transformation at the temperatures of interest is positive.

Figure 4 shows a series of decomposition runs in terms of reaction rate as a function of time (as calculated from the rate of mercury detected) at constant temperature. Each of the runs was performed in air with a flow rate of $6.2 \mathrm{~L} / \mathrm{min}$ and a sample size of $\sim 1 \mathrm{mg}$. Subsequent runs showed no difference between the decomposition in air and the decomposition in nitrogen.

The simplest conceivable mechanism for the reaction is where breaking of the mercury-sulfur bond is the rate-determining step in the reaction. If this mechanism is correct, the reaction is first order in mercuric sulfide, and the rate of the reaction as a function of time should follow the equation

$$
R(\mathrm{t})=k Q_{0} \exp (-k t),
$$

where $k$ is the rate constant of the reaction, $Q_{0}$ is the initial quantity of mercuric sulfide present, and $t$ is time. For a reaction that proceeds according to Eq. 7, a plot of the logarithm of the rate versus time is a straight line with a slope of $-k$. 


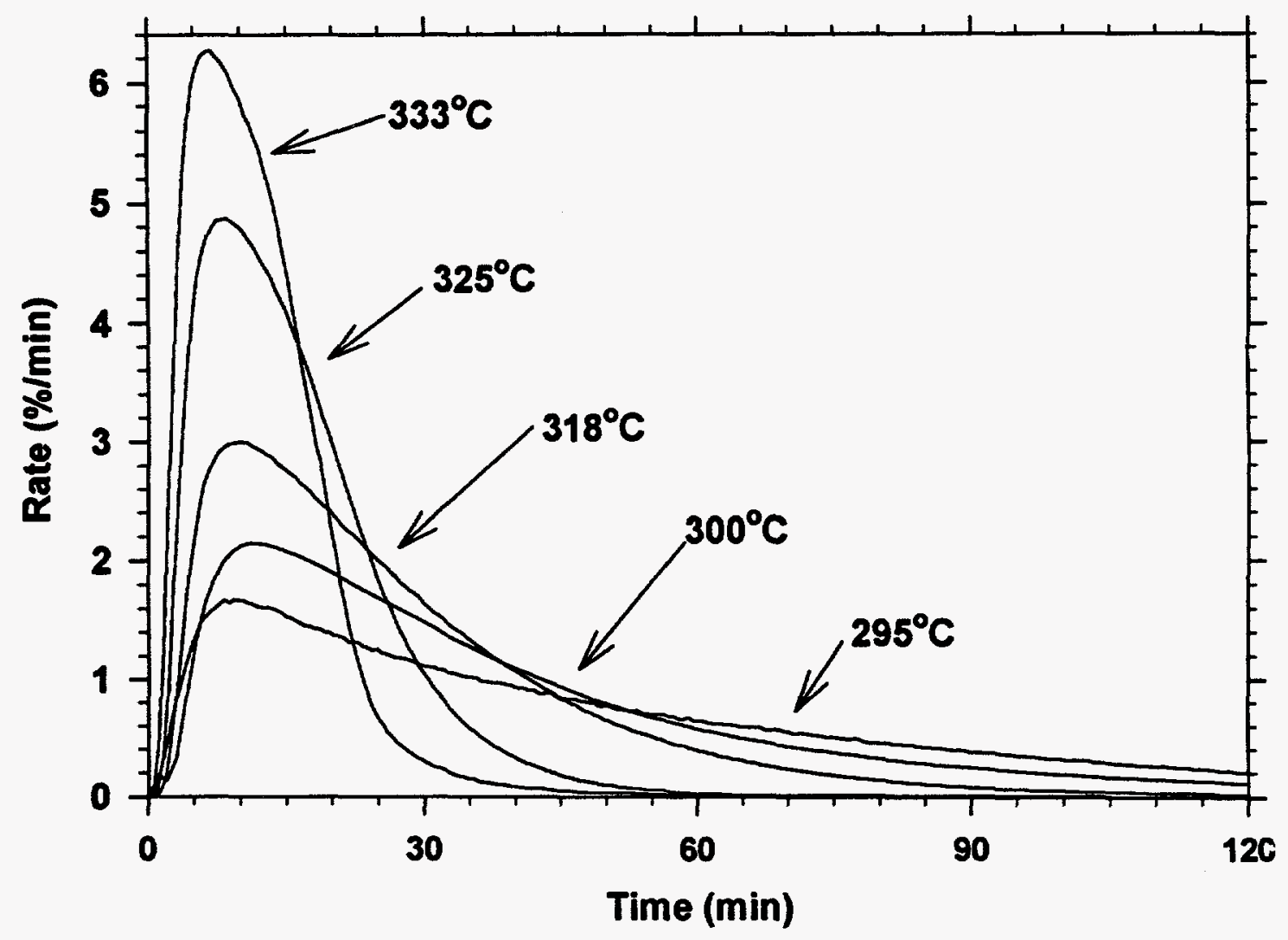

Fig. 4. Rate-versus-time profiles at selected temperatures for several constant temperature runs.

Figure 5 shows a plot of the logarithm of the rate versus time for a particular reaction at $335^{\circ} \mathrm{C}$ and the rate and temperature as a function of time. As can be seen in the graph, the logarithm of the rate does not approach a straight line until more than 30 min of reaction time and the rate has dropped to less than $1 / 4$ of its initial value. Thus, Equation 7, and the mechanism which it describes, is not completely valid. 


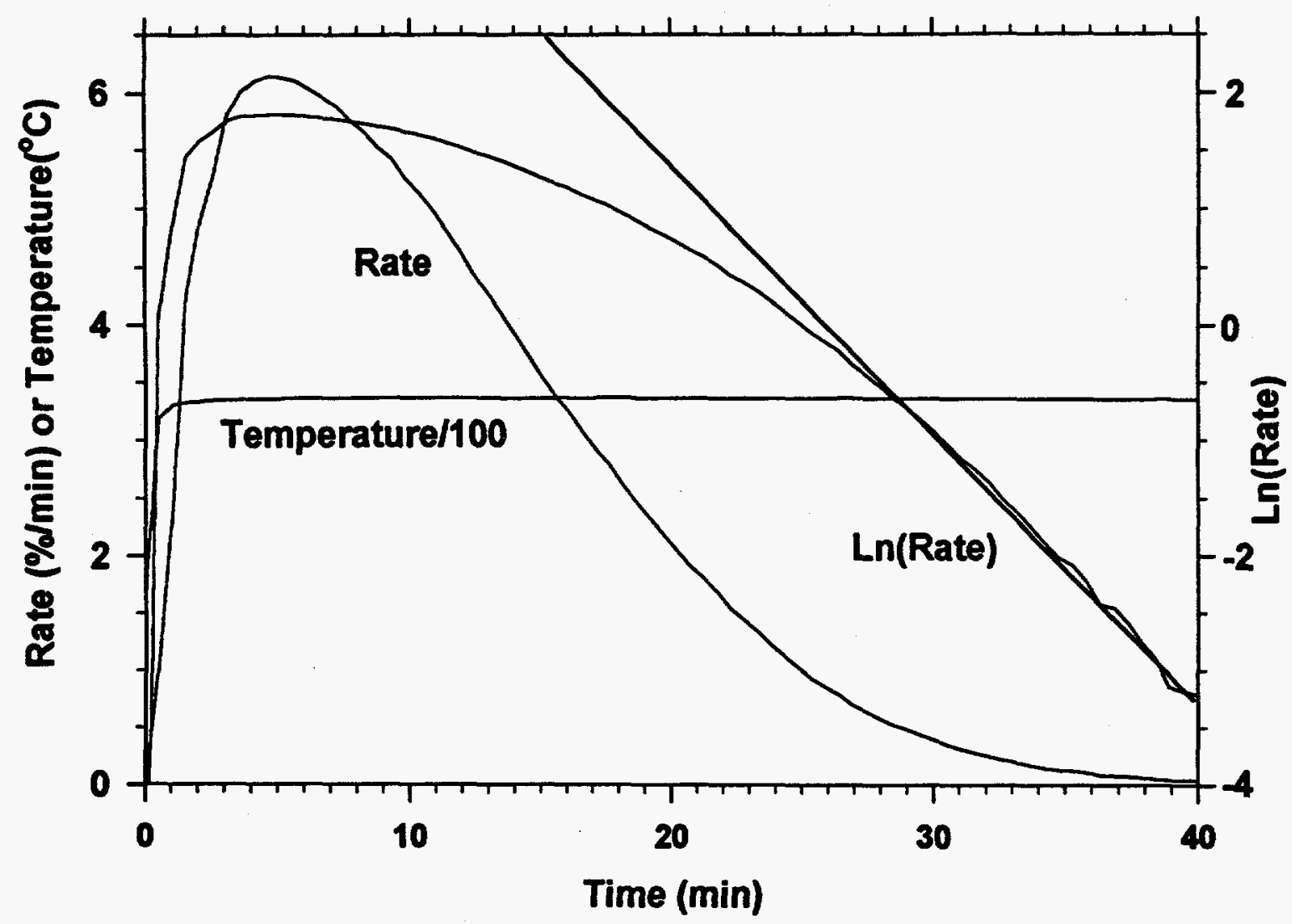

Fig. 5. Rate, $\operatorname{Ln}($ Rate), and temperature as a function of time for a particular run at $335^{\circ} \mathrm{C}$. The $\ln ($ Rate)-versus-time curve approaches a straight line at about $28 \mathrm{~min}$ of reaction time, as indicated by the tangential line on the graph.

Several factors could account for the deviation between the measured results and that predicted by Eq. 7. Since the slope of the Ln(Rate) curve is smaller for the initial portion of the reaction than the long-time limit, the rate is initially slower than that of an exponential decay. This fact could be the result of a slower heat-up time for the sample than that indicated by the thermocouple reading because the thermocouple is reading the gas-phase temperature near but not exactly in contact with the sample holder. Another possibility is that the chemical reaction mechanism is more complicated than what was proposed earlier. For instance, the rate of formation of the $S_{2}$ molecule may be affecting the results. Still another possibility is that the evolved mercury is interacting with the surfaces of the system (quartz tube inside the furnace, connecting tubing to detector, and Tygon® tubing inside the EPM analyzer) and is being detected at a slower rate than it is being evolved. If such is the case, the chemical reaction - mercury transport mechanism can possibly be described by 


$$
\mathrm{HgS}(\mathrm{s}) \stackrel{k_{c}}{\rightarrow} 1 / 2 \mathrm{~S}_{2}(\mathrm{~g})+\underset{\mathrm{k}_{1} 11 \mathrm{k}_{-}}{\mathrm{Hg}(\mathrm{g})} \stackrel{k_{p}}{\rightarrow} \mathrm{Hg}(\text { det }),
$$

where $k_{c}$ is the chemical decomposition rate constant (same as the rate constant defined by Eq. 7), $k_{p}$ is the pumping constant, $k_{s}$ is the rate constant corresponding to condensation of mercury vapor onto surfaces of the system, $k_{-s}$ is the rate constant corresponding to evaporation of mercury from surfaces, $\mathrm{Hg}(\mathrm{s})$ is the amount of mercury absorbed on the surfaces, and $\mathrm{Hg}($ det $)$ is mercury that has reached the ultraviolet detector. Unfortunately, none of these rate constants is known $a$ priori. Although the rate-versus-time data can be fit to the system of differential equations that represent Eq. 8, four adjustable parameters (the four rate constants) are to be fit. Although some of the experimental runs were analyzed this way, the rate constant values determined from the least squares fits of the data did not always vary systematically.

Instead of attempting to determine in detail the chemical reaction and transport operation steps in this process, we analyzed the experimental runs by determining the limiting slope of the Ln(Rate)-versus-time plots over a range of temperatures and calculating a pseudo-rate constant using the equation

$$
k=- \text { slope } \text {. }
$$

This $k$ can be interpreted as producing the maximum possible observable decomposition rate at a given temperature. The temperature dependence of the rate constants, $k(T)$, is then interpreted in terms of the Arrhenius Equation,

$$
k=A \exp \left(-E_{d} / R T\right),
$$

where $A$ is the pre-exponential factor, $E_{\alpha}$ is the activation energy, $R$ is the gas constant, and $T$ is the temperature in Kelvin. If $\ln (k)$ is plotted versus $T$, the data, according to the Arrhenius equation, will fit a straight line with slope $-E_{d} / R$. Figure 6 shows such a plot. From the slope of the best fit line (in the sense of least squares) through the data, the activation energy for the reaction is calculated to be $55 \mathrm{kcal} / \mathrm{mol}$. Note that some of the runs were performed in air (labelled with circles in Fig. 6) and some were performed in nitrogen (squares). No difference in the reaction rate was detected as a result of this change in carrier gas. 


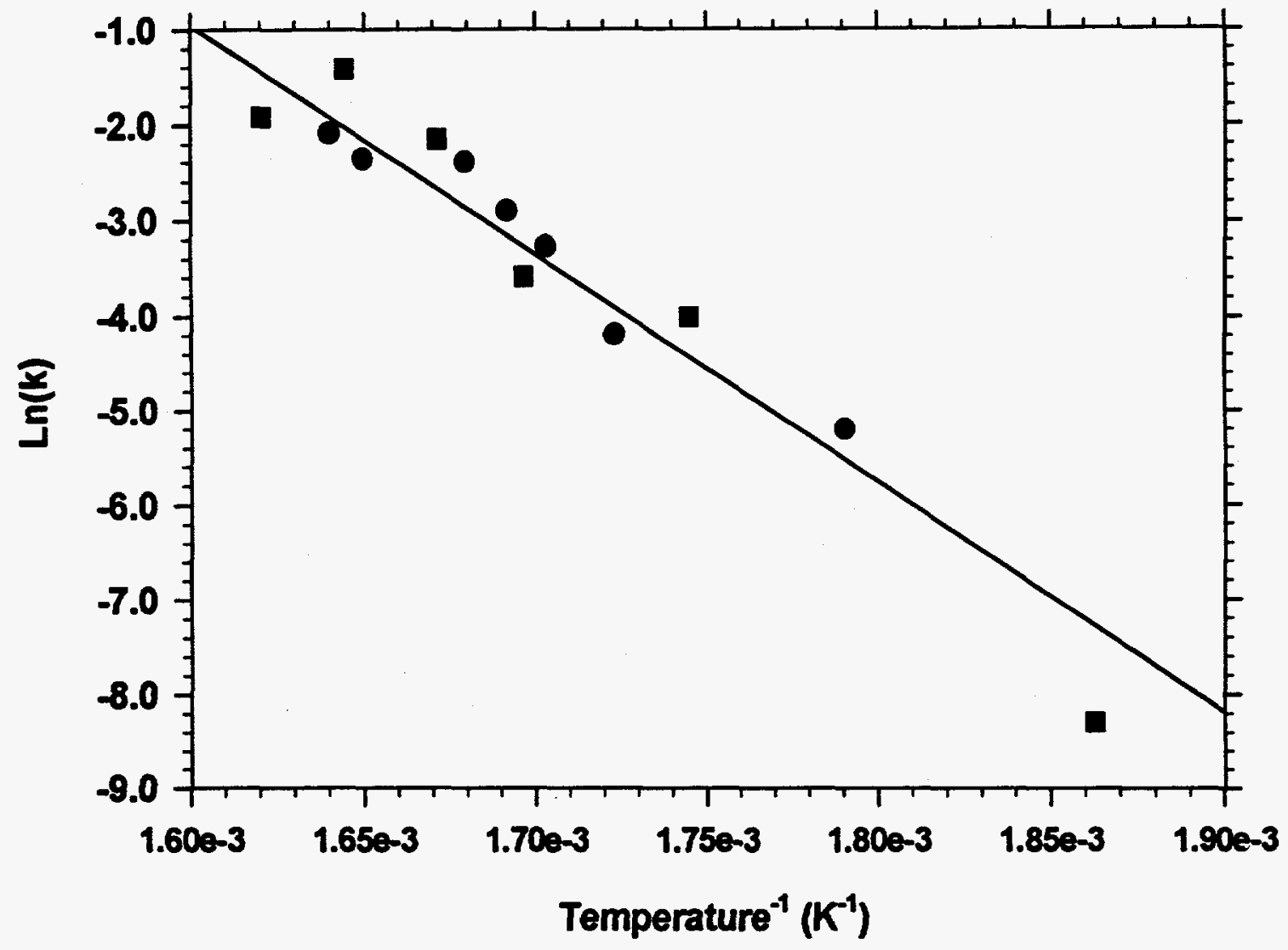

Fig. 6. Arrhenius plot of rate constants determined from the time dependence of individual decomposition runs at constant temperature. Points designated by circles are from runs made in air; points designated by squares are from runs made in nitrogen. Using a linear least squares fit to all of the data results in an activation energy of $55 \mathrm{kcal} / \mathrm{mol}$. 


\section{PRACTICAL RESULTS}

The results from the preceding section can be formulated in terms of practical results that can be used to predict the decomposition rate of $\mathrm{HgS}$ as a function of time and temperature. From the reciprocal temperature axis intercept, the data shown in Fig. 6 can be used to determine $A$, the pre-exponential factor in Eq. 10, which is $6.5 \times 10^{18} \mathrm{~min}^{-1}$. This value and the activation energy determine the temperature dependence of the first-order rate constant. The time dependence of the reaction is defined by Eq. 8 . For a reaction that occurs at constant temperature, Eq. 8 can be integrated to determine the quantity of $\mathrm{HgS}$ decomposed as a function of time. The results of this study can then be put in the form

$$
Q(t)=Q_{0}[1-\exp (-k t)],
$$

where the temperature dependence of $k$ is given by

$$
k(T)=6.5 \times 10^{18} \exp (-27680 / T)
$$

Note that the relative amount of $\mathrm{HgS}$ decomposed at any given time (extent of reaction) is independent of the initial amount present and that the Qs may be in units of weight, concentration, or quantity. Thus Eq. 11 predicts, for example, that debris containing $1000 \mathrm{ppm}$ of $\mathrm{HgS}$ will take the same amount of time to be reduced to $100 \mathrm{ppm}$ of $\mathrm{HgS}$ as debris containing $100 \mathrm{ppm}$ of $\mathrm{HgS}$ will take to be reduced to $10 \mathrm{ppm}$ of $\mathrm{HgS}$. The results indicated by Eq. 11 and 12 can be put in graphical form as shown in Fig. 7 by the three curves which are numerically labelled. Because of the relatively large activation energy involved, small increases in the temperature of the reaction result in large increases in the rate of the reaction.

Using Eq. 7, it is also a simple matter to model a non-constant temperature profile such as a ramped heat-up period prior to a constant hold temperature thermal treatment. Although this results in a nonlinear differential equation to solve, the solution is numerically straightforward and trivial to obtain using a computer. Fig. 7 also shows the result (curve labelled R\&H) for the numerical solution of Eq. 7 for a particular ramp-hold-cool-down cycle. The cycle is defined by a linear heating rate from room temperature to $320^{\circ} \mathrm{C}$ over a period of 15 minutes, followed by a 75 minute hold at $320^{\circ} \mathrm{C}$, and a linear cool-down period to room temperature over 15 minutes. Note that for this more realistic cycle, no significant amount of decomposition occurs until the $\mathrm{HgS}$ reaches its hold temperature, nor does it occur during the cool-down period. For this cycle, only $93 \%$ of the $\mathrm{HgS}$ is predicted to be decomposed. 


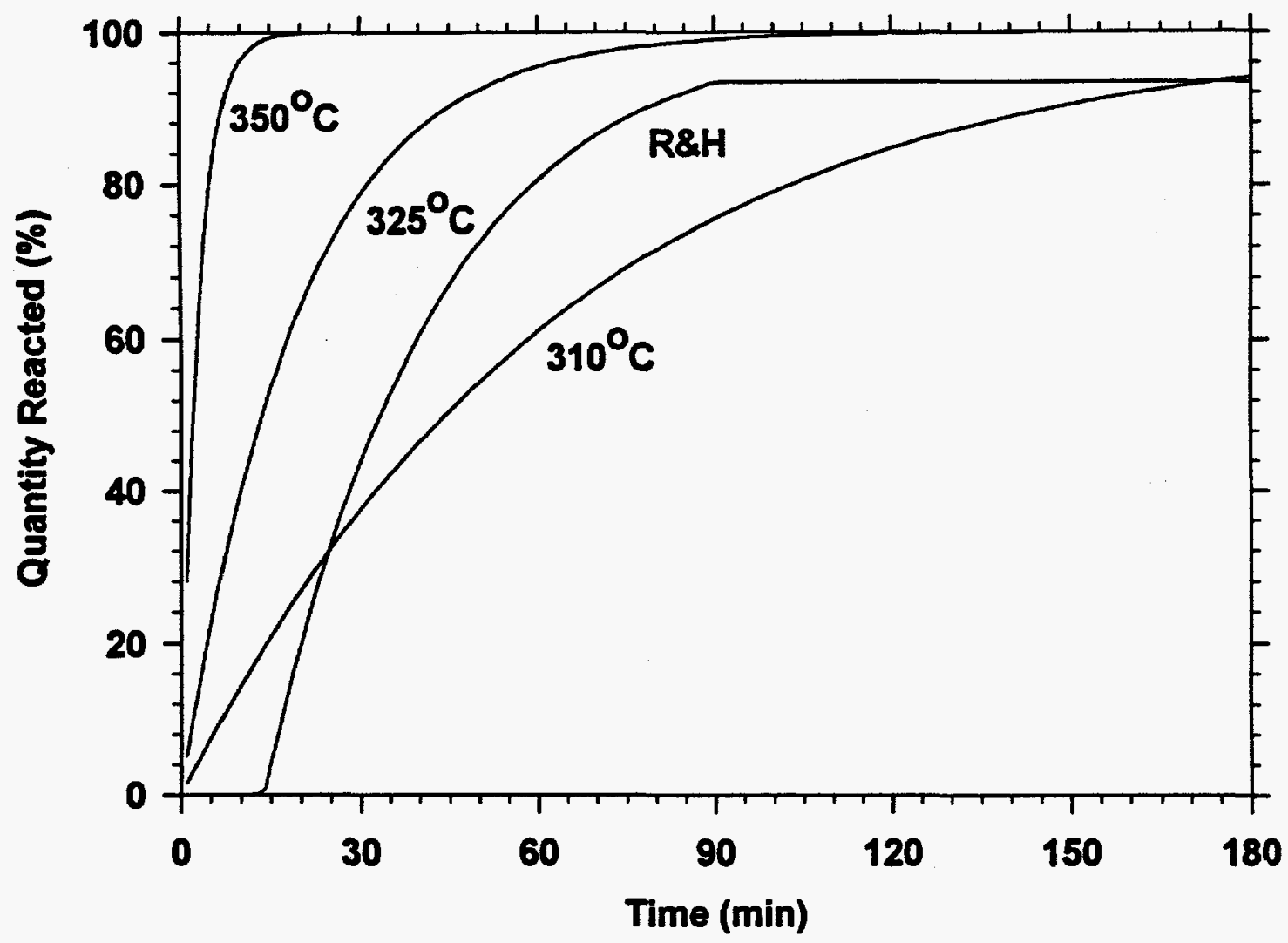

Figure 7. Prediction of mercuric sulfide decomposition quantity as a function of time for several temperature cycles. The numerically labelled curves are for constant temperature runs, while the curve labelled R\&H includes a linear heat-up period for 15 minutes, followed by 75 minutes at $320^{\circ}$, and a 15 minute cool-down period. 


\section{COMPARISON WITH LARGE-SCALE STUDIES}

As was discussed in the introduction to this report, there is considerable interest in the thermal treatment of mercury-contaminated soils and debris. At least three studies ${ }^{5,6}$ have been performed to test the possibility of treatment of large quantities of materials. All of these tests used soils but not necessarily of identical matrix and mercury content. Although the results of this study cannot be compared directly with the results of these large-scale studies, they can be compared for consistency and used to interpret the large-scale results. Table 1 summarizes the results by the large-scale studies.

Table 1. Summary of results of large-scale studies

\begin{tabular}{lclrccc}
\hline Study & $\begin{array}{c}\text { Initial } \\
\text { total Hg } \\
(\mathrm{ppm})\end{array}$ & $\begin{array}{c}\text { Carrier } \\
\text { gas }\end{array}$ & $\begin{array}{c}\text { Treatment } \\
\text { time }(\mathrm{min})\end{array}$ & $\begin{array}{c}\text { Treatment } \\
\text { temperature } \\
\left({ }^{\circ} \mathrm{C}\right)\end{array}$ & $\begin{array}{c}\text { Final } \\
\text { total Hg } \\
(\mathrm{ppm})\end{array}$ & $\begin{array}{c}\text { Percentage } \\
\text { removed } \\
(\%)\end{array}$ \\
\hline $\mathrm{VFL}^{5}$ & 330 & steam & 94 & 203 & 24 & 93 \\
$\mathrm{VFL}^{5}$ & 362 & air & 94 & 300 & 26 & 95 \\
$\mathrm{VFL}^{5}$ & 213 & air & 125 & 290 & 26 & 88 \\
$\mathrm{IT}^{5}$ & 503 & air & 10 & 350 & 15 & 97 \\
$\mathrm{IT}^{5}$ & 285 & air & 10 & 600 & 8 & 97 \\
$\mathrm{MMES}^{6}$ & 560 & nitrogen & 65 & 500 & 5 & 99 \\
MMES $^{6}$ & 380 & nitrogen & 65 & 500 & 5 & 99 \\
\hline
\end{tabular}

Based on the information generated in this study, the VFL result at $203^{\circ} \mathrm{C}$ indicates that most of the mercury desorbed in that run was probably elemental mercury or possibly some organic form of mercury. The remaining $24 \mathrm{ppm}$ of total mercury could be present as either $\mathrm{HgS}$ or mercuric oxide $(\mathrm{HgO})$. The fact that $26 \mathrm{ppm}$ of total mercury remained after the VFL run at $300^{\circ} \mathrm{C}$ indicates that the remaining mercury is probably $\mathrm{HgO}$. If it had been $\mathrm{HgS}$, one would have expected the percentage that was removed (last column) to have increased more significantly over the corresponding value for the $203^{\circ} \mathrm{C}$. The VFL run at $290^{\circ}$ also suggests that the remaining mercury is present as $\mathrm{HgO}$. Another possibility is that the transport of some or all of the mercury from the soil is hindered by nonchemical means (e. g. bull diffusion).

The IT runs at $350^{\circ}$ and $600^{\circ} \mathrm{C}$ are consistent with most of the total mercury being present as either $\mathrm{HgS}$ or elemental mercury. The mercury remaining in the soil after these runs is likely to be present as $\mathrm{HgO}$.

The MMES runs at $500^{\circ} \mathrm{C}$ are, in general, consistent with the VFL and IT data, which support the conclusion that the soils contained a significant amount of elemental mercury and a 
small amount of $\mathrm{HgO}$. However, one might have expected a $>99 \%$ removal efficiency for the MMES runs based on the data in this report and some unpublished scoping studies on $\mathrm{HgO}$ decomposition. As mentioned previously, the small amount of mercury present at the end of the runs may not be $\mathrm{HgO}$, and may be due to a small amount of mercury (in any form) being hindered from removal by a bulk diffusion effect. 


\section{CONCLUSIONS AND FUTURE WORK}

The thermal decomposition of $\mathrm{HgS}$ likely proceeds as a first-order chemical reaction with the temperature dependence of the rate constant well described by the Arrhenius equation. The implications of these findings are that thermal treatment of $\mathrm{HgS}$ - containing waste needs to be performed at temperatures in excess of $300^{\circ} \mathrm{C}$ if the total mercury content of the waste is to be reduced by a factor of 50 or more in less than $2 \mathrm{~h}$.

Surface interaction effects between mercury vapor and the reaction system surfaces were apparent, slowing the mercury vapor transport to both the detector and presumably the vent. This effect is likely to be the case in larger systems as well, particularly if metal surfaces are present. No attempt was made in this study to derive a quantitative model for the surface interaction that was suspected. The authors recommend that this issue be an item for future investigations, with such materials of construction as quartz, Teflon®, and stainless steel (both polished and unpolished) being considered for investigation.

Although some data related to the thermal decomposition of other mercury species such as elemental mercury and mercuric oxide were acquired in this study, a more detailed investigation of both those materials and mercuric chloride is highly desirable to aid in the design of large-scale mercury treatment systems. 


\section{REFERENCES}

1. RCRA Regulations and Keyword Index, Table 2, 40 CFR, Part 268.42, p. 651, Elsevier Science, Inc., New York, 1994.

2. M. O. Barnett et al., "Characterization of Mercury in Contaminated Floodplain Soils," Emerging Technologies in Hazardous Waste Management VI, 2, 1292, American Chemical Society, 1994.

3. RCRA Regulations and Keyword Index, Table 3, p. 659, Elsevier Science, Inc., New York, 1994.

4. D. R. Lide and H. V. Kehiaian, CRC Handbook of Thermophysical and Thermochemical Data, CRC Press, Boca Raton, Fla., 1994.

5. R. J. Sams et al., "Thermal Treatment of Multiple Mercury Species in Lower East Fork Poplar Creek Floodplain Soils," Emerging Technologies in Hazardous Waste Management VI, 2, 1303, American Chemical Society, 1994.

6. R. H. Krabill et. al, "Thermal Desorption of Mercury and PCB-Contaminated Wastes," Emerging Technologies in Hazardous Waste Management $V I, 1,163$, American Chemical Society, 1994. 


\section{Distribution}

Oak Ridge K-25 Site

Kimmitt, $\mathbf{R}$.

Oak Ridge National Laboratory

Conley, T. B.

Gilliam, T. M.

Turner, R. R.

Oak Ridge Y-12 Plant

Baker, M. L.

Calhoun, C. L.

Cecala, C. M.

Childs, Y. C.

Cline, J. E.

Gillis, G. A.

Gorin, A. H.

Kitzke, K. A.

Krabill, R. A.

Leckey, J. H. (3)

Lee, A. K / DOE-OSTI (2)

Little, D. K.

Nulf, L. E.

Reiner, R. H.

Sams, R. J.

Shippy, J. L.

Simon, K. F.

Smith, D. D.

Y-12 Central Files (RC) 